\title{
Virus respiratorios. Sucedió lo esperado. ¿Y ahora qué?
}

Respiratory viruses: Things happened as expected. And now what?

En forma inesperada el surgimiento de un nuevo virus, en este caso el coronavirus tipo 2 (SARS-CoV-2), responsable de la actual pandemia (COVID-19) remodela los aspectos epidemiológicos de otras enfermedades. ¿De qué manera la experiencia adquirida puede ayudar a encontrar respuestas para problemas de salud pública que llevan años sin solución?

La bronquiolitis que afecta en forma predominante a lactantes pequeños, es la principal causa de hospitalización infantil estacional en nuestro país y en casi todo el mundo. El virus sincicial respiratorio (VSR), un virus que infecta todos los grupos etarios es su principal agente causal. Aún no se ha logrado el desarrollo de inmunizaciones seguras para la edad pediátrica. Se están evaluando nuevas vacunas que, administradas a embarazadas y adultos mayores, podrían disminuir el riesgo de transmisión a los niños que son quienes sufren las complicaciones más graves.

Dado que comparten similares mecanismos de transmisión, era esperable que las medidas tomadas para intentar contener la pandemia por COVID-19 especialmente el aislamiento, el distanciamiento social y las medidas de higiene, incidieran también sobre la transmisión del VSR y otros virus respiratorios. Pero debemos ser cuidadosos con ese pronóstico, porque aún no disponemos de datos estadísticos completos del año 2020 y no sabemos qué ocurrió con los niños de poblaciones más vulnerables que viven en condiciones de hacinamiento, sin acceso a agua potable y con dificultades para acceder a los servicios de salud.

En este número de Archivos Argentinos de Pediatría se publica el trabajo de Lución y col. sobre el impacto del COVID-19 en la circulación de virus respiratorios en un hospital pediátrico. ${ }^{1}$ En ese estudio se observó una reducción del $73 \%$ en las tasas de hospitalización por bronquiolitis y neumonía no COVID-19 comparando los años 2019 y 2020, en coincidencia con datos nacionales y de otras partes del mundo. ${ }^{2}$ Hubo también una marcada reducción en la detección de otros virus respiratorios, y no se diagnosticó ningún caso de VSR que había sido el agente más frecuente $(71,2 \%)$ en el año testigo.

A nivel nacional, la reducción en casos de bronquiolitis en menores de 2 años fue notoria. En el año 2019, y en concordancia con los 7 años previos, el número de casos fue de 227685 mientras que en 2020 fue de 36230 y en 2021 se registraron 80476 casos hasta la semana epidemiológica $42 .^{3}$

En los estudios nacionales de vigilancia de virus respiratorios del corriente año 2021 hasta la semana 42, fueron positivas casi 3300000 muestras examinadas para SARS- CoV-2. Sólo se examinaron 30000 muestras en todas las edades para otros virus respiratorios. El $99 \%$ de todas las muestras positivas correspondieron a SARSCoV-2. Luego del marcado descenso de otros virus respiratorios (VSR, influenza, parainfluenza, adenovirus) producido en 2020, vuelven a detectarse en 2021 especialmente el VSR en niños, siguiendo el patrón estacional habitual entre las semanas 11 y $34 .{ }^{3}$ Esto coincide con la liberación paulatina de las medidas de aislamiento, aunque está muy lejos aún de alcanzar los niveles previos a la iniciación de la pandemia.

¿Bajo qué características se presentará la BQL en los próximos meses? Se están observando algunas variaciones de las formas de presentación en distintas partes del mundo, como el resurgimiento de las infecciones por VSR fuera de su período estacional, o un aumento en el número de internaciones de niños de mayor edad con cuadros respiratorios graves "no bronquiolitis" producidos por VSR. ${ }^{4,5}$ Estos niños mayores sin contacto previo con el virus aumentan la población susceptible.

Es evidente que las medidas implementadas para restringir la circulación del COVID-19, han logrado también reducir la circulación de los otros virus respiratorios. Estudios realizados utilizando modelos matemáticos que tienen en cuenta el aumento de las poblaciones susceptibles concluyen en que es posible que, al levantarse estas medidas denominadas no farmacológicas, se produzca la aparición de grandes brotes tanto de infecciones por VSR como por virus influenza. ${ }^{6}$

Es preocupante también la posibilidad de resurgimiento de enfermedades controladas por vacunas como el sarampión, ya que durante la pandemia se ha producido una reducción de hasta un $50 \%$ en la concurrencia a vacunatorios.

Este es el momento de considerar diferentes 
aspectos sobre las enfermedades transmisibles y no transmisibles, sus características distintivas, su posibilidad de transformarse en epidémicas, pandémicas o endémicas, así como de analizar en qué forma las medidas tomadas para contener algunas impactan sobre otras.

En este contexto adquieren vigencia los conceptos acuñados bajo la denominación de "sindemia" por el médico y antropólogo Merrill Singer en la década de los 90 y retomados con motivo de la actual pandemia. ${ }^{7}$ Poner un nombre a los hechos ayuda a definirlos.

Una epidemia involucra una población susceptible, un agente causal y sus vías de contagio. Pero el concepto de sindemia es mucho más amplio. Expresa una sinergia entre distintas epidemias y su interacción biológica, lo que incide a su vez en grupos poblacionales con desiguales condiciones sociales, económicas y ambientales; esto obliga a tomar diferentes políticas de salud para obtener resultados exitosos en la prevención o la mitigación.

Dos o más enfermedades o condiciones interactúan causando un daño mayor que la suma de cada una de ellas. En el caso de COVID-19, involucra una enfermedad infecciosa, la edad del huésped y un grupo de enfermedades no transmisibles, que se desarrollan a su vez en diversas regiones geográficas, diferentes poblaciones con variada movilidad y densidad, con sistemas de salud en diferentes niveles de desarrollo. Los resultados pueden ser marcadamente asimétricos en cuanto a morbilidad y mortalidad.

Vemos como año tras año, el VSR afecta la salud de los más pequeños. Del análisis de su comportamiento durante la pandemia por COVID-19 debieran surgir medidas innovadoras, tal vez más efectivas que la búsqueda, hasta ahora infructuosa, de tratamientos específicos. Todo apunta hacia la prevención, especialmente si tenemos en cuenta que más del $50 \%$ de los niños de nuestro país se encuentran bajo la línea de pobreza. ${ }^{8-10}$

Como puntualiza Richard Horton en su comentario en The Lancet, visualizar las epidemias como sindemias "invita a una visión más amplia que incluye actuar sobre la educación, el empleo, la vivienda, la alimentación y los cuidados del medio ambiente".${ }^{11}$ En el caso específico de la bronquiolitis, agregamos a todas esas condiciones, asegurar la accesibilidad oportuna al sistema de salud.

\section{Susana Rodríguez (ID)}

Editora asistente

http:/ / dx.doi.org/10.5546/ aap.2022.78

Texto completo en inglés:

http:/ / dx.doi.org/10.5546/ aap.2022.eng.78

Cómo citar: Rodríguez MS. Virus respiratorios. Sucedió lo esperado. ¿Y ahora qué? Arch Argent Pediatr 2022;120(2):78-79.

\section{REFERENCIAS}

1. Lución MF, Juárez MV, Pejito MN, Orqueda AS, et al. Impacto del COVID-19 en la circulación de virus respiratorios en un hospital pediátrico: una ausencia esperada. Arch Argent Pediatr 2022;120(2):99-105.

2. Ferrero F, Ossorio MF. Is there a place for bronchiolitis in the COVID-19 era? Lack of hospitalizations due to common respiratory viruses during the 2020 winter. Pediatr Pulmonol. 2021;56(7):2372-3.

3. Argentina. Ministerio de Salud de la Nación. Boletín Integrado de Vigilancia semanal N572. SE 42/2021. [Consulta: 2 de diciembre de 2021]. Disponible en: https: / / bancos.salud.gob.ar/ recurso/boletin-integrado-devigilancia-n572-se-422021

4. Agha R, Avner JR. Delayed seasonal RSV surge observed during the COVID-19 pandemic. Pediatrics. 2021;148(3):e2021052089.

5. Hussain F, Kotecha S, Edwards MO. RSV bronchiolitis season 2021 has arrived, so be prepared! Arch Dis Child. 2021;106(12):e51.

6. Baker RE, ParkSW, Yang W, Vecchi GA, et al. The impact of COVID-19 nonpharmaceutical interventions on the future dynamics of endemic infections. Proc Natl Acad Sci U S A. 2020;117(48):30547-53.

7. Singer M, Bulled N, Ostrach B, Mendenhall E. Syndemics and the biosocial conception of health. Lancet. 2017;389(10072):941-50.

8. Rodríguez MS. La bronquiolitis en el año del COVID-19. Arch Argent Pediatr 2020;118(3):222-3

9. Argentina. Instituto Nacional de Estadísticas y Censos. Condiciones de vida. Vol.4, $n^{\circ} 4$. Incidencia de la pobreza y la indigencia en 31 aglomerados urbanos. Segundo semestre de 2019. [Consulta: 2 de diciembre de 2021]. Disponible en: https: / /www.indec.gob.ar/uploads/informesdeprensa / eph_pobreza_02_195EFE752E31.pdf

10. UNICEF Argentina. La pobreza y la desigualdad de niñas, niños y adolescentes en la Argentina. Efectos del COVID-19. Buenos Aires; UNICEF: 2020. [Consulta: 2 de diciembre de 2021]. Disponible en: https://www. unicef.org / argentina / media / 8096 / file/COVID-19:\%20 La\%20pobreza $\% 20 y \% 201$ \% $\% 20$ desigualdad $\% 20$ de $\% 20$ ni $\%$ C $3 \%$ B1as, $\% 20$ ni $\%$ C $3 \%$ B1os $\% 20$ y $\%$ 20adolescentes $\% 20$ en\%20la\%20Argentina..pdf

11. Horton R. Offline: COVID-19 is not a pandemic. Lancet. 2020;396(10255):874. 